\title{
Successfully extraction of plucked VDD pacemaker lead with myocardial biopsy catheter and macro snare
}

\author{
E. Ozdemir*, S. Emren, N. Kahya Eren, C. Nazli, M. Tokac \\ Izmir Katip Celebi University, Cardiology Department, Turkey
}

\section{A R T I C L E I N F O}

\section{Article history:}

Received 12 October 2017

Accepted 16 October 2017

Available online 18 October 2017

\section{Keywords:}

Percutaneous lead extraction

Femoral vein

Snare

Biopsy catheter

\begin{abstract}
A B S T R A C T
35 year old patient with Ebstein anomaly and operated atrial septal defect (ASD) was referred to our hospital due to VDD pacemaker lead dysfunction. We decided to remove dysfunctional lead via subclavian lead extraction procedure. After pacemaker generator had been removed, lead was cut to insert locking stylet but plucked lead entrapped in subclavian vein. Then 7-F femoral sheath was introduced to femoral vein and plucked lead was pulled back via myocardial biopsy catheter from inferior vena cava. Finally macro snare was used to taken out lead from femoral vein. The procedure was successfully managed without complication.

(c) 2017 The Society of Cardiovascular Academy. Production and hosting by Elsevier B.V. All rights reserved. This is an open access article under the CC BY-NC-ND license (http://creativecommons.org/licenses/by-nc-nd/4.0/).
\end{abstract}

\section{Introduction}

Transcatheter lead extraction procedure increasing globally and became a successful method to extract the leads of permanent pacemakers and implantable cardioverter defibrillators. ${ }^{1}$ To develop a specialized equipment of precutaneous lead extraction procedure to succefully extract permanent pacemaker or defibrillator leads is challenging. Currently transubclavian lead extraction has been successful due to used extraction systems including locking stylets, mechanical and laser catheters. ${ }^{2,3}$ However the operator can come across some unexpected complications which should be managed by creative approaches.

In this paper we present a case who had undergone successfully extraction of plucked VDD pacemaker lead by using myocardial biopsy and macro snare catheter during trans-sublavian lead extraction procedure.

\section{Case report}

35-year- old male patient with ebstein anomaly and operated atrial septal defect was referred to our hospital due to VDD pacemaker lead dysfunction. A lead fracture was detected at scopy (Fig. 1A). Patient was decided to undergo percutaneous lead extraction. In the catheter laboratory at first pacemaker generator had been removed and then pacemaker lead was separated from battery pocket. In next step lead

\footnotetext{
* Corresponding author at: Izmir Katip Celebi University Ataturk Education and Research Hospital, Cardiology, Basin Sitesi, Karabaglar-Izmir 35360, Turkey.

E-mail address: Emre.ozdemir7@saglik.gov.tr (E. Ozdemir).

Peer review under responsibility of The Society of Cardiovascular Academy.
}

was introduced into locking stylet to extract the lead completely. At this time lead was cut, the lead suddenly slipped to subclavian vein. A7-F femoral sheath was.

Introduced in femoral vein and the procedure was continued via femoral access. First macro-snare inserted in 7 F-guiding right Judkins catheter and tried to catch proximal broken tip of lead in the subclavian vein but this attempt failed because of the hard adhesion of lead to vein. Than out of routine myocardial biopsy catheter was advanced to subclavian vein via femoral vein sheath. This is a 7-F Cordis ${ }^{\circledR}$ long myocardial biopsy catheter with $2.3 \mathrm{~mm}$ jaw and $104 \mathrm{~mm}$ length. The plucked lead was grasped and pulled back via myocardial biopsy catheter until inferior vena via (Fig. 1B, C) Lead was separated into two wire due to stripping of the insulation cover (Fig. 1D).

These separated wires were catched by macro snare via femoral access(Fig. 2A). Lead was taken out from femoral sheat, while snare was being pulled back with controlled force (Fig. 2B, C) There was no residual lead fragment in the heart (Fig. 2D). Therefore a combined lead extraction procedure was successfully completed.

\section{Discussion}

Planned percutaneous extraction procedure for especially old and firmly adhered leads can cause important complications related to venous, cardiac system and pacemaker or ICD leads. Mediastinal hemorrhage, lead fractures, venous access problems and pulmonary embolism are the most severe complications that surgical intervention can be needed. The outcome and the risk of the lead extraction should be evaluated on patient basis. The complication risk of percutaneous lead extraction is much dependent on the experience of the operator. 


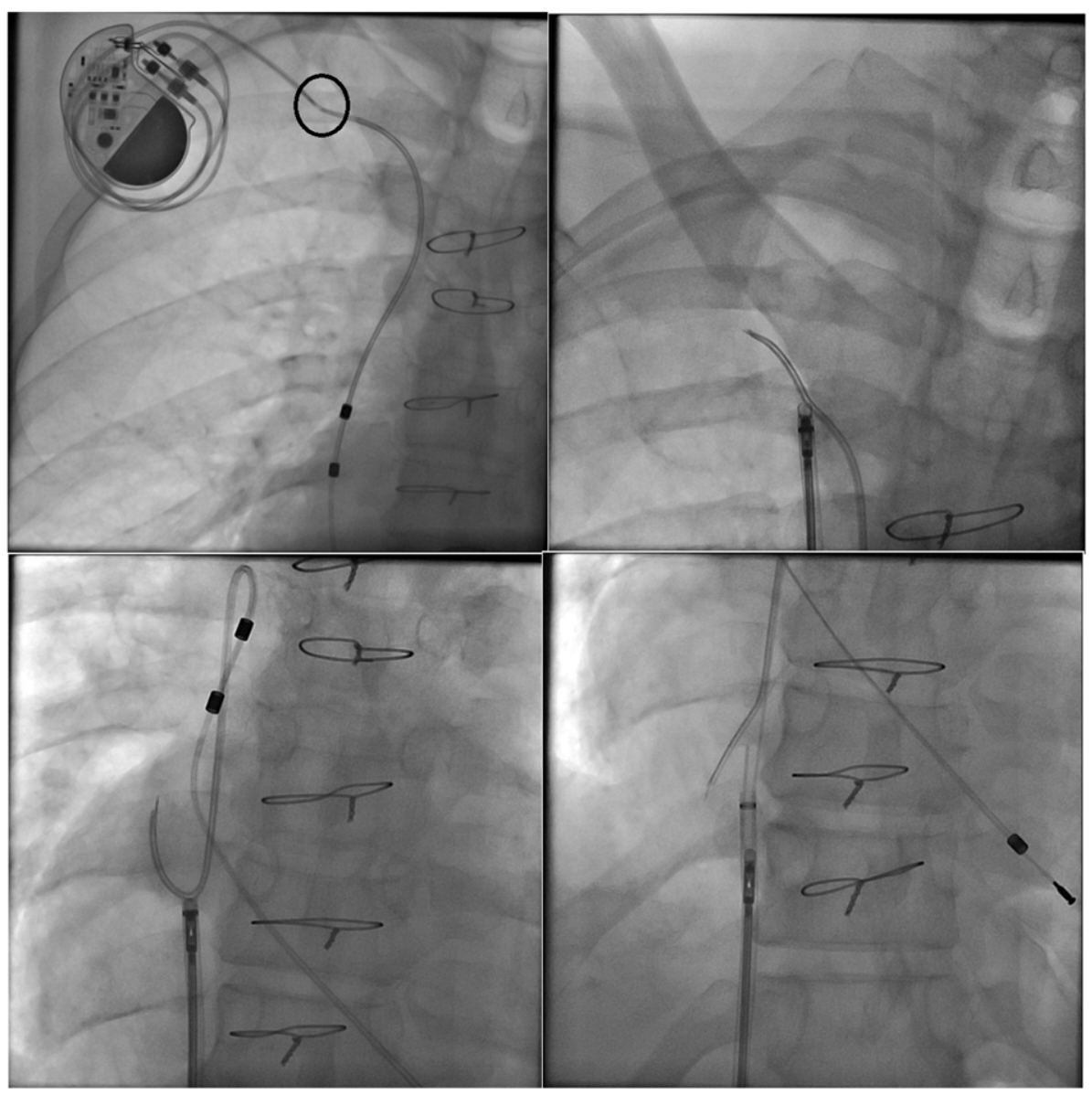

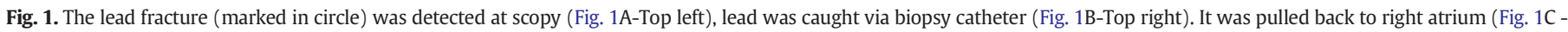
bottom left). Lead was separated into two wire due to stripping of the insulation cover (Fig. 1D - bottom right).

Complication rates of permanent pacemaker lead extraction is approximately $1,4 \%{ }^{4}$ Although specialized equipment has been developed percutaneous extraction $^{5}$ of permanent pacemaker or defibrillator leads is already a challenging procedure. The use of locking stylets, mechanical dilatator and laser catheters lead to improve succession rate of transsubclavian extraction procedure. ${ }^{2}$ Despite all these advanced devices complete extractions considered fragments $<4 \mathrm{~cm}$ are left ${ }^{3}$ otherwise complete extractions may be succeed in $88 \%-93 \%$ of all attempts. ${ }^{6}$ On the other hand, femoral access can use as alternative or complementary way to get success in some unexpected situtations. "Drag through technique" ${ }^{\text {, }}$, needle eye snare (Cook Medical) and some other procedures (snare and ablation catheter or pigtail catheter combinated usage) can be useful for transfemoral lead extraction. The superior approach can be performed with simple traction with using a locking stylet and a mechanical sheath, was safe and effective for the extraction of leads. As with our case lead extraction via the inferior approach is the only interventional method for free-floating leads, as the proximal end of the lead cannot be approached from the generator pocket, this approach is essential for pulling the lead from the SVC to the right atrium in the failed process of subclavian lead extraction. ${ }^{8}$ However our case was required a complex and nonroutine technique for lead extraction due to unexpected technical problems. For example, Lelakowski, Jacek, et al. defined extraction of 15-years-old DDD pacemaker lead with a pigtail loop was formed to free the head or the proximal end of the adhered atrial lead and was pulled into the femoral vein using the pigtail loop with the Dotter ${ }^{\circledR}$ (Cook Medical) basket ${ }^{9}$, other example Jo, Uk, et al. introduced 23 consecutive patients (43 leads) who underwent transvenous lead extraction using a Amplatz GooseNeck® Snare and
10 consecutive patients (17 leads) who underwent lead extraction using simple manual traction as a result of this study Jo, Uk, et al. found transvenous extraction of pacemaker leads via an inferior approach using a gooseneck snare was both safe and effective but, transvenous extraction of defibrillator leads using the inferior approach was suboptimal. ${ }^{10}$ Also as a different study Schleifer, J. William et al. presented a case removal of a densely adherent hardware because of the extensive fibrosis using the combination of RF ablation with the wire and Amplatz GooseNeck® is a potential tool for removing adherent pacing lead fragments. ${ }^{11}$

As described in these studies our case included a complex inferior approach, first we tried to catch lead's proximal broken tip via macro snare that was inserted in $7 \mathrm{~F}$ right Judkins guiding catheter from femoral vein sheath but this attempt became unsuccessful as a radical decision to grasp plucked lead via myocardial biopsy catheter, instead of macro snare since the proximal tip of the lead was quite above just entrapped in subclavian vein which make it difficult the catch via macro snare and we pulled back the lead till IVC via a 7-F Cordis ${ }$ long myocardial biopsy catheter, we used macro snare to completely extract plucked lead. This is the first case at literature because of using biopsy cathater to extract lead. After procedure we done there was no residual lead fragment in the heart. Therefore a combined lead extraction procedure was successfully complete via a way that not described before using a biopsy catheter. At our case biopsy catheter could wound the subclavian vein or vena cava, as a result of this injury, mortal complications like bleeding to pleura or mediastinum. So different and undefined techniques can be a solution for unexpectable situations in interventional cardiology during it is combined with experience. 


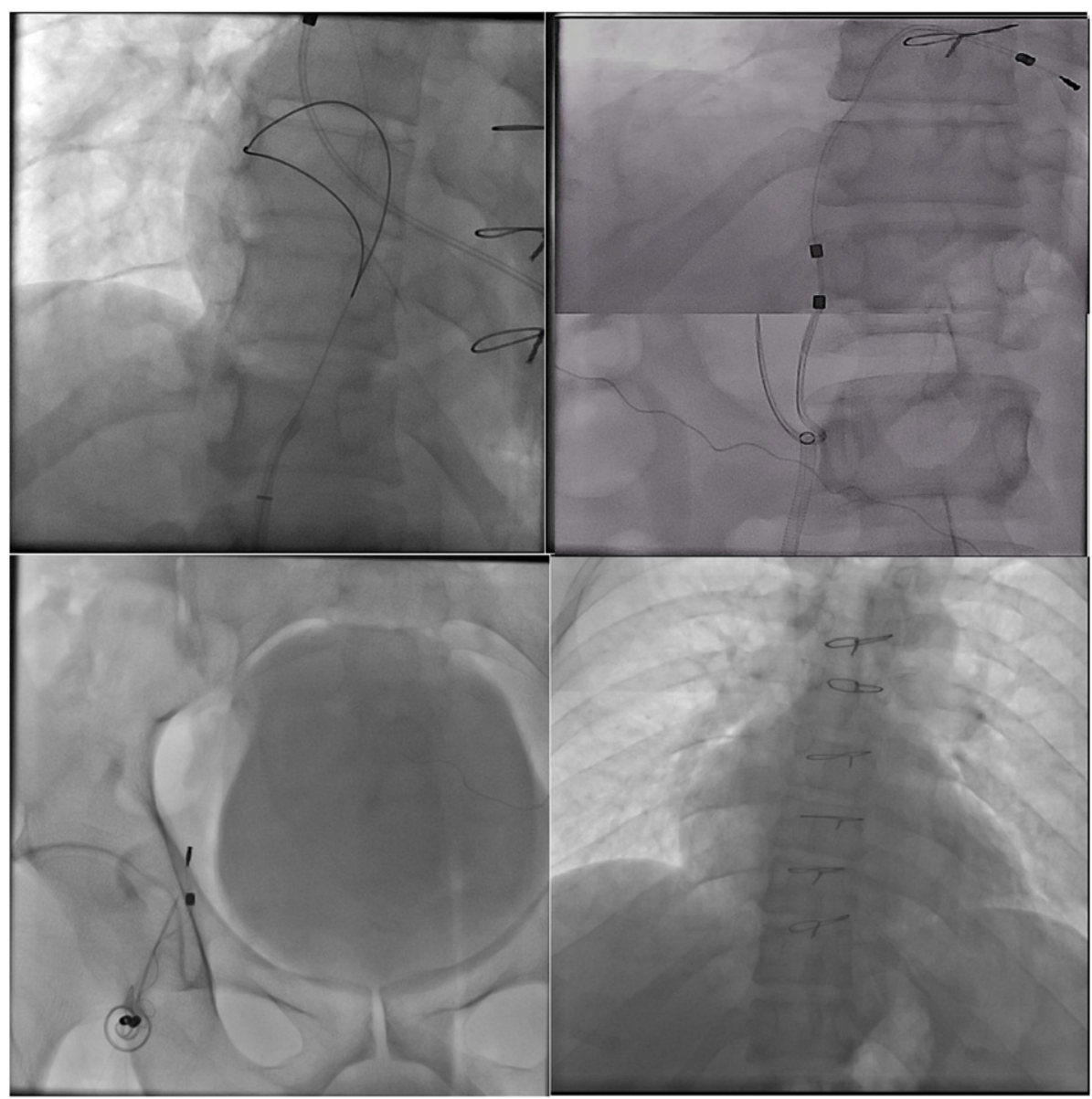

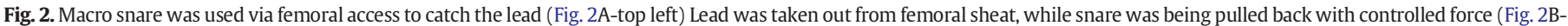
top right, 2C-bottom left). There was no residual lead fragment in the heart (Fig. 2D-bottom right).

\section{Conclusion}

Transfemoral access can be needed especially in case of free-floating and plucked leads during transsubclavian lead extraction procedure. If the plucked lead entrapped in subclavian vein, transfemoral way can be tried to completely extract the lead by using myocardial biopsy catheter and macro snare respectively.

\section{Acknowledgements}

The authors declare that there is no conflict of interest regarding the publication of this article.

The patient had given written and verbal informed consent.

This case was presented on 33rd Turkish Cardiology Congress with International Participation as a verbal presentation.

\section{References}

1. Mond HG, Proclemer A. The 11th world survey of cardiac pacing and implantable cardioverter-defibrillators: calendar year 2009-a World Society of Arrhythmia's project. Pacing Clin Electrophysiol 2011;34:1013-1027.
2. Byrd CL, Schwartz SJ, Hedin NB, Goode LB, Fearnot NE, Smith HJ. Intravascular lead extraction using locking stylets and sheaths. Pacing Clin Electrophysiol 1990;13(12 Pt 2):1871-1875.

3. Neuzil P, Taborsky M, Rezek Z, et al. Pacemaker and ICD lead extraction with electrosurgical dissection sheaths and standard transvenous extraction systems: results of a randomized trial. Europace 2007;9:98-104.

4. Byrd CL, Wilkoff BL, Love CJ, et al. Intravascular extraction of problematic or infected permanent pacemaker leads 1994-1996. PACE 1999;22:1348-1357.

5. Wilkoff BL, Byrd CL, Love CJ, et al. Pacemaker lead extraction with the laser sheath: results of the pacing lead extraction with the excimer sheath (PLEXES) trial. J Am Coll Cardiol 1999;33:1671-1676.

6. Bordachar Pierre, et al. Extraction of old pacemaker or cardioverter defibrillator leads by laser sheath versus femoral approach. Circulation 2010 (CIRCEP-109).

7. Schilling RJ, et al. Replacement of extracted permanent pacemaker or defibrillator leads by cannulation of veins using the femoral "drag through" technique. Heart 2002;87:276-278.

8. Bongiorni MG, Soldati E, Zucchelli G, et al. Transvenous removal of pacing and implantable cardiac defibrillating leads using single sheath mechanical dilatation and multiple venous approaches: high success rate and safety in more than 2000 leads. Eur Heart J 2008;29:2886-2893.

9. Lelakowski Jacek, et al. Complex percutaneous extraction of a 15-year-old atrial lead dislodged into the subclavian vein. Arch Med Sci 2011;7(1):164.

10. Jo U, Kim J, Hwang YM, et al. Transvenous lead extraction via the inferior approach using a gooseneck snare versus simple manual traction. Kor Circ J 2016;46(2): 186-196.

11. Schleifer JW, Shen WK, Naidu SG, et al. Radiofrequency ablation-assisted extraction of a pacing lead fragment. HeartRhythm Case Rep 2015;4(217):1. 